\title{
Lymphocyte transformation in cancer patients: variation in results according to technique
}

\author{
GILLIAN M. L. GYTE AND SYLVIA M. WATKINS \\ From the Department of Pathology and Medicine, Lister Hospital, Stevenage, Hertfordshire SG1 4AB, UK
}

SUMMARY Lymphocyte transformation to phytohaemagglutinin (PHA) was measured simultaneously by two methods (heparin and methyl cellulose) in 16 patients with non-lymphoid cancer and 21 normal subjects. Twelve cancer patients showed transformation levels below the normal heparin range, but only two patients showed levels below the normal methyl cellulose range. These findings suggest that in interpreting lymphocyte transformation studies closeattention should begiven to the methods employed.

The in-vitro response to PHA of lymphocytes from patients with non-lymphoid malignant disease is often impaired (Garrioch et al., 1970; Scheurlen and Pappas, 1971; Thomas et al., 1971; Whittaker and Clark, 1971; Watkins, 1973; Knight and Davidson, 1975). On the other hand, some workers have found normal PHA responsiveness in all patients with nonlymphoid cancers (Robinson and Hurvitz, 1966; Sutherland et al., 1971; Edwards et al., 1973; Roberts and Jones-Williams, 1974). Possibly the wide variety of techniques for estimating PHA transformation is the reason for these discrepancies. We have therefore studied cancer patients simultaneously by two methods to see whether technical variations can produce different results.

\section{Subjects and methods}

Lymphocytes from 16 patients (aged 18-73 years) with various forms of non-lymphoid cancer and 21 normal persons (aged 18-62 years) were tested by methods $A$ and $B$.

Fifty millilitres of venous blood was taken from each subject and the two methods were set up simultaneously with all procedures being carried out under sterile conditions.

\section{METHOD A: HEPARIN}

Twenty millilitres of blood was mixed with 375 units of heparin and allowed to sediment in a syringe for 30 to 60 minutes. The leucocyte rich plasma (LRP) was decanted off, the remaining blood centrifuged for 10 minutes at $2800 \mathrm{~g}$, and the plasma layer removed. The lymphocytes and total white cells in the LRP

Received for publication 14 July 1977. were counted and a master mix set up containing $1 \times 10^{6}$ lymphocytes per $3 \mathrm{ml}, 20 \%$ autologous plasma and $80 \%$ TC199 (Wellcome: containing penicillin $200 \mathrm{units} / \mathrm{ml}$ and streptomycin $100 \mu \mathrm{g} / \mathrm{ml}$ ). PHA-P (Difco) was added to a concentration of $1 \mu \mathrm{l}$ of reconstituted material per $\mathrm{ml}$ of master mix and the master mix divided into quadruplicate cultures (whenever possible) of $3 \mathrm{ml}$ in tightly stoppered tissue culture tubes (Nunc: $100 \mathrm{~mm} \times 14 \mathrm{~mm}$ ).

\section{METHOD B: METHYL CELlULOSE}

Thirty millilitres of blood was defibrinated (using glass beads in a universal bottle) and taken back into the syringe. The volume of serum present was calculated from the packed cell volume, and methyl cellulose (BDH, $1 \%$ in TC199) was added to give $33 \%$ methyl cellulose solution and $67 \%$ serum in the sample. The blood-methyl cellulose was mixed for 30 minutes, then allowed to sediment for 30 minutes, and the leucocyte-rich serum-methyl cellulose was decanted off and spun on the bench centrifuge for 10 minutes at $500 \mathrm{~g}$. The serum-methyl cellulose was removed, the cells were washed three times in TC199 and then resuspended in $3 \mathrm{ml}$ of TC199, and the lymphocytes and total white cells counted. A master mix was set up containing $1 \times 10^{6}$ lymphocytes per $3 \mathrm{ml}, 30 \%$ autologous serum-methyl cellulose (hence $20 \%$ autologous serum) and $70 \%$ TC199. PHA-P (1 $\mu \mathrm{l} / \mathrm{ml}$ of master mix) was added and quadruplicate cultures of $3 \mathrm{ml}$ were set up as in method A.

The cultures set up by both methods were incubated for three days at $37^{\circ} \mathrm{C}$ and tritiated thymidine (Radiochemical Centre: $3 \cdot 0 \mu \mathrm{Ci}$, specific activity $0 \cdot 1$ $\mathrm{Ci} / \mathrm{mmol}$ ) was added to each culture four hours before harvesting. The incubation was stopped by the addition of ice-cold saline, the samples spun for 
10 minutes at $2800 \mathrm{~g}$, and the supernatant decanted. The samples were washed again with ice-cold saline, then twice with ice-cold trichloroacetic acid $(5 \%)$ and once with absolute alcohol. Soluene $3500.5 \mathrm{ml}$ (Packard) was added to each, and after at least two hours the samples were transferred to liquid scintillation vials using $10 \mathrm{ml}$ NE233 scintillation fluid (Nuclear Enterprises). After two to three days the radioactivity of the samples was measured on a Nuclear Enterprises NE 8312 Spectrophotometer and the efficiency of counting determined either by channels ratio or by internal standards.

The results were expressed as uptake of thymidine in pmol/106 lymphocytes $/ 4 \mathrm{~h}$ and were calculated from the following equations:

specific activity of ${ }^{3} \mathrm{H}$-thymidine $=0.1 \mathrm{Ci} / \mathrm{mmol}$

$1 \mu \mathrm{Ci} \equiv 2.22 \times 10^{6}$ disintegrations $/ \mathrm{min}(\mathrm{dpm})$

hence $1 \mathrm{pmol}$ of thymidine $\equiv 222 \mathrm{dpm}$

hence uptake of thymidine in pmol =

$$
\frac{\text { counts per minute }}{\% \text { efficiency }} \times \frac{100}{222}
$$

\section{Results}

The normal range of results using the two techniques is shown in the Figure. The heparin method gave a higher range and mean value in the normal subjects compared with the methyl cellulose method. The results in four out of the 16 cancer patients were normal by both methods and will not be considered further. The results in all 12 of the remaining patients were below the normal heparin range but only two were below the normal methyl cellulose range.

\section{Discussion}

Most of the cancer patients had normal lymphocyte responses when assessed by the methyl cellulose method, while three-quarters of the results were below the normal range by the heparin method. By contrast the normal range was much lower using the methyl cellulose technique.

Analysis of the results of other workers shows that all those who used heparin and autologous serum in preparing the lymphocyte cultures found a proportion of cancer patients with subnormal responsiveness to PHA (Garrioch et al., 1970; Scheurlen and Pappas, 1971; Thomas et al., 1971; Whittaker and Clark, 1971; Watkins, 1973; Knight and Davidson, 1975). On the other hand, those who used washed cells and non-autologous serum found consistently normal PHA responses (Robinson and Hurvitz, 1966; Sutherland et al., 1971; Roberts and Jones-Williams, 1974). These results are easily explained since the

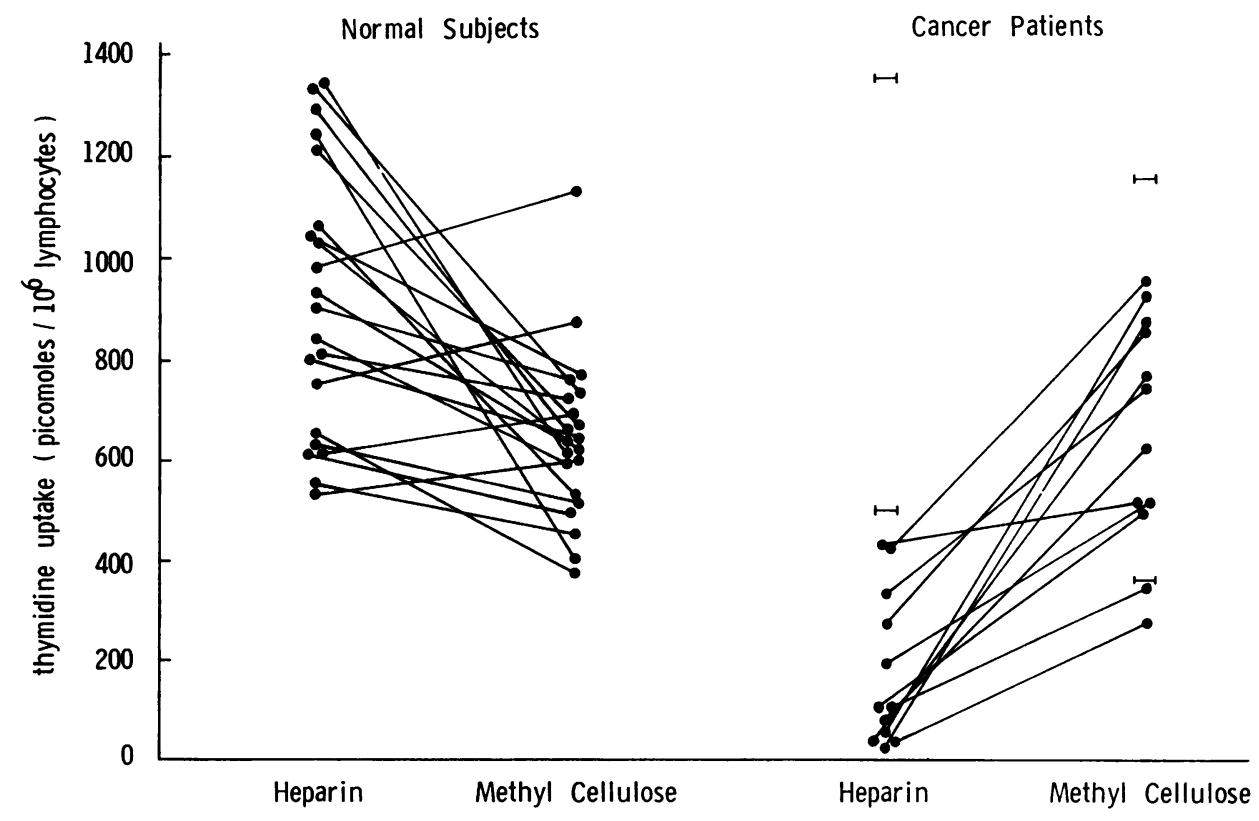

Figure Lymphocyte response to PHA in normal subjects and cancer patients by two methods 
lymphocytes themselves are probably normal and the impaired responsiveness is due to humoral factors, possibly produced by or near the malignant tissue (Silk, 1967; Gatti, 1971; Scheurlen and Pappas, 1971; Whittaker and Clark, 1971; Edwards et al., 1973). Workers using other techniques including methyl cellulose, gelatin, dextran, Ficoll-Isopaque, Ficoll-Triosil, Ficoll-Hypaque, and whole blood have found variable results (Whittaker and Clark, 1971; Catalona et al., 1973; Mekori et al., 1974; Nemoto et al., 1974; Roberts and Jones-Williams, 1974; Barnes et al., 1975; Blomgren et al., 1975; Kaplan et al., 1975; Kumar and Taylor, 1975).

We have shown that the heparin and methyl cellulose techniques give very different results in the same patient. This discrepancy may be caused through chemical interference by the reagents used in the methyl cellulose method on the humoral factors which depress lymphocyte responsiveness.

A peptide, found in small amounts in normal human serum and associated with the $\alpha_{2}$-globulin fraction, inhibits lymphocyte responsiveness to PHA (Riggio et al., 1969; Occhino et al., 1973). This peptide, immunoregulatory alphaglobulin (IRA), is believed to play a role in the feedback control of the cellular immune response (Riggio et al., 1969; Glasgow et al., 1974). Patients with various forms of non-lymphoid cancer have been shown to have raised amounts of $\alpha_{2}$-globulin (Ablin, 1972) and of IRA and IRA-like peptides in their serum compared with normal subjects (McLaughlin and Brooks, 1974; Nimberg et al., 1975). This serum peptide may inhibit lymphocyte responsiveness to PHA (and antigen) by binding to a plasma membrane receptor which is different from the mitogenic receptor. This binding either interferes with the mitogenic binding or prevents, at an early stage, the metabolic processes which the mitogen normally stimulates, hence inhibiting lymphocyte blastogenesis (Cooperband et al., 1972).

In this methyl cellulose technique for measuring lymphocyte responsiveness to PHA possibly the methyl cellulose prevents the binding of the inhibitor at the lymphocyte surface (either competitively or non-competitively) or the methyl cellulose binds the $\alpha_{2}$-globulin in solution, thus permitting a normal blastogenic response to PHA.

We have looked at only two methods for determining PHA responsiveness. Many other techniques have been employed by others, while some have not stated their method. In view of our findings we suggest that reports on lymphocyte responsiveness in cancer patients should be interpreted with caution and with due regard to the technique used. Clearly it would be ideal to have a standard technique in all laboratories.
We are indebted to the North-West Thames Regional Health Authority for financial support.

\section{References}

Ablin, R. J. (1972). Cancer, immunological surveillance, and $\alpha_{2}$ globulin (Letter). Lancet, 2, 874-875.

Barnes, E. W., Farmer, A., Penhale, W. J., Irvine, W. J., Roscoe, P., and Horne, N. W. (1975). Phytohemagglutinin-induced lymphocyte transformation in newly presenting patients with primary carcinoma of the lung. Cancer, 36, 187-193.

Blomgren, H., Wasserman, J., and Glas, U. (1975). Capacity of sera from patients with mammary carcinoma to promote PHA-stimulation of human lymphocytes. Acta Radiologica, 14, 127-138.

Catalona, W. J., Sample, W. F., and Chretien, P. B. (1973). Lymphocyte reactivity in cancer patients: correlation with tumour histology and clinical stage. Cancer, 31, 65-71.

Cooperband, S. R., Badger, A. M., Davis, R. C., Schmid, K., and Mannick, J. A. (1972). The effect of immunoregulatory $\alpha$ globulin (IRA) upon lymphocytes in vitro. Journal of Immunology, 109, 154-163.

Edwards, A. J., Rowland, G. F., and Lee, M. R. (1973). Reduction of lymphocyte transformation by a factor produced by gastrointestinal cancer. Lancet, 1, 687689.

Garrioch, D. B., Good, R. A., and Gatti, R. A. (1970). Lymphocyte response to P.H.A. in patients with nonlymphoid tumours (Letter). Lancet, 1, 618.

Gatti, R. A. (1971). Serum inhibitors of lymphocyte responses (Letter). Lancet, 1, 1351-1352.

Glasgow, A. H., Menzoian, J. O., Nimberg, R. B., Cooperband, S. R., Schmid, K., and Mannick, J. A. (1974). An immunosuppressive peptide fraction in the serum of cancer patients. Surgery, 76, 35-42.

Kaplan, M. S., Mino, F. O., Kummerfeld, K. B., and Lundak, R. L. (1975). Phytohemagglutinin stimulated immune response: assay in colorectal carcinoma patients. Archives of Surgery, 110, 1217-1220.

Knight, L. A. and Davidson, W. M. (1975). Reduced lymphocyte transformation in early cancer of the breast. Journal of Clinical Pathology, 28, 372-376.

Kumar, S. and Taylor, G. (1975). The response to phytohaemagglutinin (PHA) of lymphocytes from cancer patients. Journal of Clinical Pathology, 26, 476479.

McLaughlin, A. P. and Brooks, J. D. (1974). A plasma factor inhibiting lymphocyte reactivity in urologic cancer patients. Journal of Urology, 112, 366-372.

Mekori, T., Sher, S., and Robinson, E. (1974). Suppression of the mitogenic response to phytohemagglutinin in malignant neoplasia. Correlation with clinical stage and therapy. Journal of the National Cancer Institute, 52, 9-12.

Nemoto, T., Han, T., Minowada, J., Angkur, V., Chamberlain, A., and Dao, T. L. (1974). Cell mediated immune status of breast cancer patients: evaluation by skin tests, lymphocyte stimulation, and counts of rosette-forming cells. Journal of the National Cancer Institute, 53, 641-646. 
Nimberg, R. B., Glasgow, A. H., Menzoian, J. O., Constantian, M. B., Cooperband, S. R., Mannick, J. A., and Schmid, K. (1975). Isolation of an immunosuppressive peptide fraction from the serum of cancer patients. Cancer Research, 35, 1489-1494.

Occhino, J. C., Glasgow, A. H., Cooperband, S. R., Mannick, J. A., and Schmid, K. (1973). Isolation of an immunosuppressive peptide fraction from human plasma. Journal of Immunology, 110, 685-694.

Riggio, R. R., Schwartz, G. H., Bull, F. G., Stenzel, K. H., and Rubin, A. L. (1969). $a_{2}$-globulins in renal graft rejection: effects on in vitro lymphocyte function. Transplantation, 8, 689-694.

Roberts, M. M. and Jones-Williams, W. (1974). The delayed hypersensitivity reaction in breast cancer. British Journal of Surgery, 61, 549-552.

Robinson, E. and Hurvitz, D. (1966). In vitro studies of lymphocytes from cancer patients. Israel Journal of Medical Sciences, 2, 80-81.

Scheurlen, P. G. and Pappas, A. (1971). Untersuchungen über die Beeinflussung immunologischer Reaktionen 으 durch maligne Prozesse. Verhandlungen der Gesellschaft für innere Medizin, 77, 749-752.

Silk, M. (1967). Effect of plasma from patients with carcinoma on in vitro lymphocyte transformation. Cancer, 20, 2088-2089.

Sutherland, R. M., Inch, W. R., and McCredie, J. A. (1971). Phytohemagglutinin (PHA)-induced transformation of lymphocytes from patients with cancer. of Cancer, 27, 574-578.

Thomas, J. W., Coy, P., Lewis, H. S., and Yuen, A.(1971). Effect of therapeutic irradiation on lymphocyte transformation in lung cancer. Cancer, 27, 1046-1050.

Watkins, S. M. (1973). The effects of surgery on lymphocyte transformation in patients with cancer. Clinical and Experimental Immunology, 14, 69-76.

Whittaker, M. G. and Clark, C. G. (1971). Depressed lymphocyte function in carcinoma of the breast. British Journal of Surgery, 58, 717-720. 